\title{
Assessment of knowledge, attitude and practice regarding diabetes management among general practitioners in India
}

Rakesh Mehra ${ }^{1}$, Anuj Kumar ${ }^{1}$, Pushkar Kumar ${ }^{1}$, Sandeep Bhalla, Ranjit Unnikrishnan², V. Mohan², D. Prabhakaran ${ }^{1}$ ${ }^{1}$ Public Health Foundation of India, New Delhi, India, ${ }^{2}$ Dr. Mohan's Diabetes Education Academy, Chennai, India

\section{INTRODUCTION}

- Non-communicable diseases (NCDs) kill 38 million people each yea

- In 2014 the global prevalence of diabetes was estimated to be $9 \%$ among adults (WHO,

2014) with more than $80 \%$ of diabetes deaths occur in LMICs (WHO, 2014)

- India with no exception home to more than 69.2 million people suffering from diabetes

- General practitioners are the key service providers for diabetes due to skewed distribution of specialists

- The quality of care depends on their awareness, attitude and perception regarding diabetes

So this paper aims to assess the knowledge, attitude and practice regarding diabetes and its management among general practitioners in India.

\section{METHODOLOGY}

Sample Population - 2251 general practitioners enrolled under India's biggest capacity building program i.e. Certificate Course in Evidence Based Diabetes Management (CCEBDM) in 2017 to 2018. CCEBDM is a joint collaboration program between Public Health Foundation of India (PHFI), Dr. Mohan's Diabetes Education Academy (DMDEA) and is supported by educational fund from MSD Pharmaceuticals India pvt. Itd.

Study Design - Cross sectional survey

Data collection tool - Pretested close ended questionnaire comprising of questions related to knowledge, skill and attitude

Data collection technique - Online survey using SurveyMonkey platform

Data analysis - statistical software for social studies (SPSS version 22.0) was used for data analysis. Proportion and percentage was used for frequency distribution and Chi square $(X 2)$ test and ANOVA was used to assess the relation between categorical variable. P value of $<0.05$ was used as the level of significance.

\section{RESULTS}

Out of total, 1426 general practitioners with mean age 36 years completed the survey.

Number (n) Percent (\%)

\begin{tabular}{llrr}
\hline Sex & Male & & \\
& Female & 953 & $(66.8 \%)$ \\
\hline Area of Practice & Cities & 473 & $(33.2 \%)$ \\
& Towns & 882 & $(61.9 \%)$ \\
& Villages & 321 & $(22.5 \%)$ \\
& & 223 & $(15.6 \%)$ \\
\hline Qualification & Without Diabetes Education & 1135 & $(79.6 \%)$ \\
& With Diabetes Education & 291 & $(20.4 \%)$ \\
\hline Affiliation & Government & & \\
& Private & 774 & $(54.3 \%)$ \\
& & 652 & $(45.7 \%)$ \\
\hline Experience & $<5$ years & 732 & $(51.3 \%)$ \\
& 6 - 10 years & 302 & $(21.2 \%)$ \\
& $11-15$ years & 129 & $(9.1 \%)$ \\
& $>15$ years & 291 & $(18.4 \%)$ \\
\hline Patient Load & General patients & & \\
& Patients with diabetes & 127.9 & \\
\hline
\end{tabular}

\section{Knowledge Assessment}

\begin{tabular}{ll}
\hline \multicolumn{2}{l}{ Category } \\
\hline Poor & Score 0 to 5 \\
Moderate & Score 6 to 10 \\
Good & Score 11 to 15 \\
\hline minimum score 0, maximum score 15
\end{tabular}

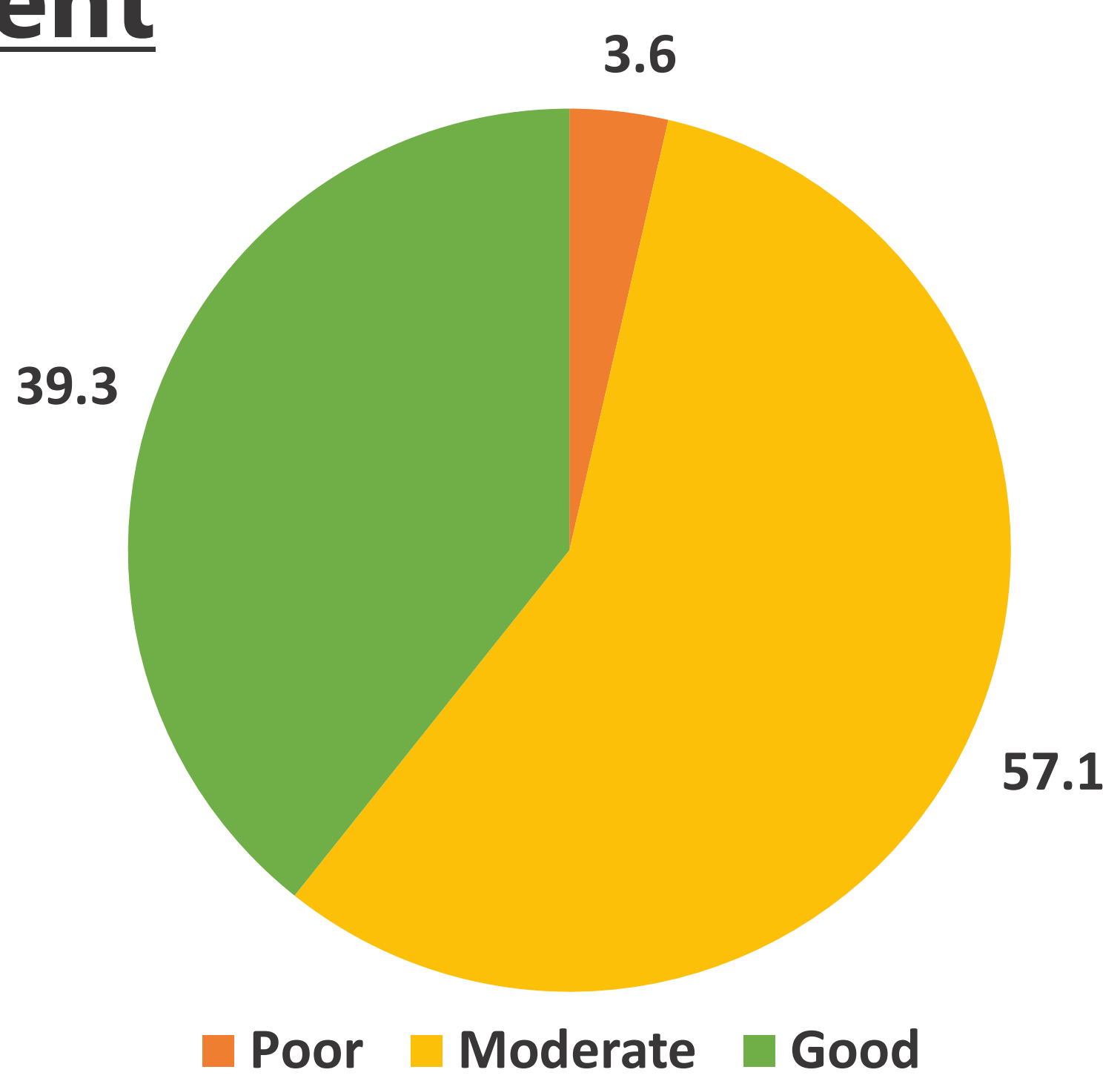

Among the sociodemographic variables, place of work $(p<0.05)$ and level of education $(p<0.05)$ are significantly associated with the higher level of knowledge.

\section{Attitude Assessment}

$93 \%$ general practitioners consider it a serious problem and believe comprehensive care is the key to better management
Barrier for Population

- Lack of knowledge - Distance - Cost of care

74.2

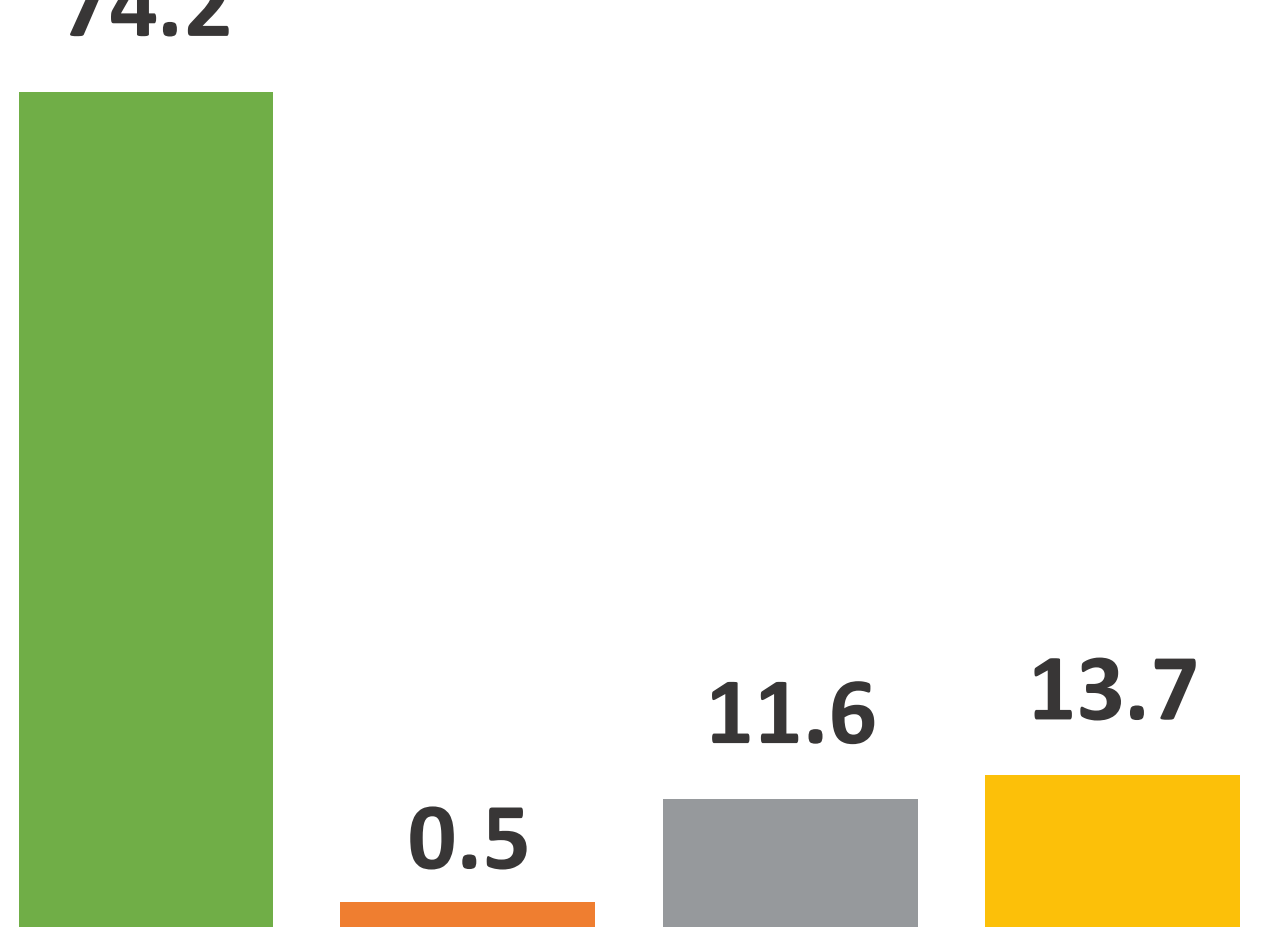

0.5

\section{Practice Assessment}

\begin{tabular}{lrr}
\hline & Number (n) & Percent (\%) \\
\hline Guidelines for diagnosis & & \\
FPG $\geq 126 \mathrm{mg} / \mathrm{dl}$ & 478 & $(33.5 \%)$ \\
Symptoms + PPBG $\geq 200 \mathrm{mg} / \mathrm{dl}$ & 223 & $(15.6 \%)$ \\
$2 \mathrm{hr}$ plasma glucose $\geq 200 \mathrm{mg} / \mathrm{dl}$ & 243 & $(17.0 \%)$ \\
HbA1c $>6.5$ & 482 & $(33.8 \%)$ \\
\hline Timing of LFT, KFT and retina check up & & \\
Half yearly & 799 & $(56.0 \%)$ \\
Yearly & 591 & $(41.4 \%)$ \\
Once in two year & 17 & $(1.2 \%)$ \\
Not at all & 19 & $(1.3 \%)$ \\
\hline Frequency of patient counselling & & \\
Always & 1288 & $(90.3 \%)$ \\
Half of the time & 99 & $(6.9 \%)$ \\
Less than half of the time & 26 & $(1.8 \%)$ \\
Never & 13 & $(0.9 \%)$ \\
\hline Frequently prescribed drug & & \\
Biguanide & 952 & $(66.8 \%)$ \\
Sulfonylureas & 382 & $(26.8 \%)$ \\
Meglitinides & 92 & $(6.5 \%)$ \\
\hline Management of complicated cases & & \\
Treat by yourself & 232 & $(16.3 \%)$ \\
Refer to specialist & 1194 & $(83.7 \%)$ \\
\hline
\end{tabular}

General practioners with higher knowledge score have positive attitude and better practice.

\section{CONCLUSION}

The study indicates that the knowledge regarding diabetes and its management is suboptimal among general practitioners. This results in poor diabetes management practices at grass root level. Therefore, capacity building of general practitioners is of utmost importance to deal with the ever increasing burden of diabetes in India. 